\title{
Estrategias de acompañamiento de madres-docentes desde una visión bidireccional del ambiente familiar y escolar*
}

\author{
Natalia Guzmán Atehortúa \\ Mónica María Álvarez Gallego ${ }^{2}$
}

Recibido: $21-03-2020$

Aceptado: 08-05-2020

\section{Resumen}

El objetivo de esta investigación es analizar las estrategias de acompañamiento que emplean madres con formación en educación durante el paso de sus hijos del ambiente familiar al escolar. Para alcanzar este propósito, fue necesario identificar dichas estrategias y, además, describir y caracterizar estos ambientes. La metodología es de enfoque cualitativo, de tipo hermenéutico y se emplea como estrategia metodológica el estudio de caso. La población investigada fueron ocho madres-docentes de la Licenciatura en Educación Preescolar de la Universidad Católica Luis Amigó. Como técnica de recolección de información se empleó la entrevista semiestructurada, y como técnicas para el análisis se realizaron

\footnotetext{
*Texto derivado del proyecto de investigación para optar al título de Magister en Educación "El paso del ambiente familiar al escolar: estrategias de acompañamiento que emplean madres con formación en educación", realizada mediante convenio con el programa de jóvenes investigadores de la Universidad Católica Luis Amigó. Artículo de investigación científica y tecnológica.

1. Licenciada en Educación Preescolar; aspirante a Magister en Educación; joven investigadora adscrita al grupo de investigación Educación, Infancia y Lenguas Extranjeras de la Facultad de Educación y Humanidades de la Universidad Católica Luis Amigó.

Correo electrónico: natalia.guzmanat@amigo.edu.co

ORCID: https://orcid.org/0000-0002-4427-1502

Google Scholar: https://scholar.google.com/citations?user=3T9yYfAAAAAJ\&hl=es

2. Profesional en Desarrollo Familiar; Especialista en Docencia Investigativa Universitaria; Magister en Salud Mental de la Niñez y la Adolescencia; coordinadora de la línea de Educación, Infancia y Familia. Grupo de investigación Educación, Infancia y Lenguas Extranjeras de la Facultad de Educación y Humanidades, del programa Licenciatura en Educación Infantil de la Universidad Católica Luis Amigó.

Correo electrónico: monica.alvarezga@amigo.edu.co

ORCID: https://orcid.org/0000-0002-3894-0554

Google Scholar: https://scholar.google.es/citations?user=sw3ZQ-kAAAAJ\&hl=es
} 
una transcripción de datos y un análisis global y profundo. Se concluye que es posible evidenciar las concepciones sobre el ambiente familiar y escolar mediante una visión bidireccional de las estrategias de acompañamiento que emplean las madresdocentes.

Palabras clave: estrategias de acompañamiento, madres, docentes, ambiente familiar, ambiente escolar.

\section{Support strategies for mothers-teachers from a two-way vision of the family and school environment}

\section{Abstract}

The objective of this research is to analyze the accompaniment strategies used by mothers with education training during the transition of their children from the family environment to the school environment. To achieve this purpose, it was necessary to identify these strategies and, in addition, describe and characterize these environments. The methodology is of a qualitative approach, of a hermeneutical type and the case study is used as a methodological strategy. The population investigated were eight mother-teachers from the Bachelor's Degree in Preschool Education from the Luis Amigó Catholic University. The semi-structured interview was used as the information gathering technique, and data transcription and a global and in-depth analysis were carried out as techniques for the analysis. It is concluded that it is possible to demonstrate the conceptions about the family and school environment through a bidirectional vision of the support strategies used by the motherteachers.

Keywords: accompaniment strategies, mothers, teachers, family environment, school environment. 


\section{Introducción}

Numerosas investigaciones relacionan a la familia y la escuela con el desarrollo personal y social de los niños (Garaigordobil, 2014) y también con el ámbito académico (Castro y García, 2016). No obstante, pocos estudios plantean una relación directa entre las estrategias de acompañamiento y los ambientes familiar y escolar, lo que sugiere la pertinencia de nuevas perspectivas de la conexión entre madres e hijos durante los diversos cambios de ambiente.

La familia y la escuela son los primeros y principales espacios donde se establecen las bases para que los niños y niñas emprendan el camino hacía una formación integral. Así lo afirma Sánchez (2012) cuando menciona algunas dimensiones del ambiente familiar que inciden en el proceso escolar de los estudiantes: "la participación de los padres en los centros escolares, la atención de los padres a los hijos y el nivel de estudios de los progenitores" ( $p$. 36). Asimismo, Espitia y Montes (2009) plantean que "cada familia tiene sus propios valores, actitudes, principios y visiones que dan sentido al apoyo en los aprendizajes de sus hijos; es decir, su capital particular e insustituible le permite usar estrategias, prácticas y metodologías diferentes" (p. 95). Esta visión es relevante, dado que las interacciones en el ambiente familiar son la base para las futuras interacciones en el ambiente escolar.

En el marco de estas consideraciones, la educación que se brinda a los niños y niñas en Colombia ha estado guiada por el papel que cumplen los ambientes familiar y escolar para garantizar este derecho. De esta forma, la familia es el "núcleo fundamental de la sociedad y primer responsable de la educación de los hijos" (art. 7, Ley 115 de 1994). Por su parte, el ambiente escolar se presenta como

la forma específica en que se relacionan y se comunican los miembros de una institución educativa, así como también a la manera en que la misma involucra a los ac- 
tores (docentes, padres y estudiantes), en el proceso de aprendizaje de los estudiantes. (Secretaría de Educación de Medellín, 2020)

Cada ambiente en el que se desenvuelven los niños y niñas está conformado por personas que cumplen roles específicos, con responsabilidades definidas. Sin embargo, falta claridad sobre sus características. Esto genera una brecha entre las perspectivas que emergen en estos ambientes. Por esta razón es necesario indagar sobre la manera en que las madres como agentes de socialización primaria de sus hijos, perciben y valoran las acciones realizadas en los ambientes familiar y escolar, especialmente en su relación directa con el sector educativo.

A partir de lo expuesto, se plantea la pregunta: ¿Cuáles son las estrategias de acompañamiento que emplean las madres en proceso de formación como licenciadas en Educación Preescolar de la Universidad Católica Luis Amigó durante el paso de sus hijos del ambiente familiar al ambiente escolar?

Para analizar esas estrategias es necesario identificarlas, y describir y caracterizar estos ambientes. También es relevante la manera en que la formación docente de estas madres aporta al acompañamiento y apoyo durante los procesos que viven los niños. De esta forma es posible conocer el modo en que estas mujeres emplean los conocimientos adquiridos durante su formación como docentes y el uso que hacen de este aprendizaje en su rol como madres.

\section{Metodología}

Esta investigación se presenta desde un enfoque cualitativo, pues a partir de la particularidad de los protagonistas se busca comprender su realidad (Galeano, 2004). Es decir, se concentra en las experiencias de los sujetos investigados y su proceso de interacción con el contexto en que se desenvuelven. Este enfoque permitió analizar 
las estrategias que emplean las participantes para acompañar a sus hijos durante el paso del ambiente familiar al escolar.

Las interacciones de investigación estuvieron mediadas por el lenguaje y orientadas hacia la interpretación y comprensión de la comunicación. Por tanto, la hermenéutica permitió una comprensión recíproca para validar la opinión de la persona investigada, a partir de una situación dialógica (Gadamer, 1993).

Por otro lado, el estudio de caso como estrategia metodológica, busca describir en detalle para comprender el objeto y los sujetos investigados. Este tipo de estudio permite incluir uno o múltiples casos, ya sea con una comunidad, una cultura, un grupo, o fenómenos como prácticas o interacciones (Sandoval, 2002). A través de esta postura, se buscó obtener una visión bidireccional de la forma en que las participantes generan las estrategias que emplean tanto en el ambiente familiar como en el escolar.

En este sentido, la población investigada está compuesta por 8 docentes en formación que estuviesen cursando los cuatro últimos semestres de la Licenciatura en Educación Preescolar de la Universidad Católica Luis Amigó, sede Medellín, y que tuvieran un hijo(a) con edades entre 2 y 7 años, que estuviese escolarizado(a). Por este motivo, en los resultados y discusión, la población tomará el nombre de madre-docente. A continuación, se detallan los aspectos sociodemográficos de la población. 
Tabla 1. Aspectos sociodemográficos de las participantes.

\begin{tabular}{|c|c|c|c|c|c|c|c|c|c|c|c|}
\hline 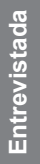 & 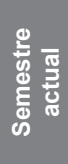 & $\frac{\mathbb{8}}{\frac{0}{0}}$ & $\begin{array}{l}\text { 윰 } \\
\text { 윰 }\end{array}$ & 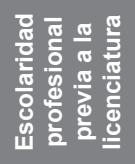 & 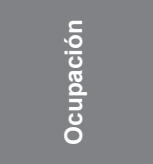 & 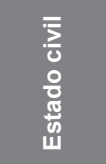 & $\frac{\frac{\pi}{0}}{\frac{0}{2}}$ & $\begin{array}{l}\frac{2}{0} \\
\frac{8}{8} \\
\frac{8}{\Phi} \\
\frac{2}{2}\end{array}$ & 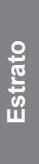 & 을 & 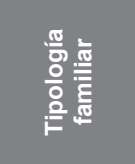 \\
\hline 1 & 8 & Finalizada & 29 & Ninguno & Estudiante & Soltera & 7 & Primero & 4 & La Mota & Extensa \\
\hline 2 & 9 & Finalizada & 35 & Ninguno & Independiente & Separada & 4 & Jardín & 4 & $\begin{array}{c}\text { Aves } \\
\text { Marías } \\
\text { Envigado }\end{array}$ & Monoparental \\
\hline 3 & 8 & 4 & 32 & Ninguno & $\begin{array}{l}\text { Docente } \\
\text { preescolar }\end{array}$ & $\begin{array}{l}\text { Unión } \\
\text { libre }\end{array}$ & 6 & Primero & 2 & $\begin{array}{l}\text { San José } \\
\text { Envigado }\end{array}$ & Nuclear \\
\hline 4 & 8 & Finalizada & 27 & Ninguno & Niñera & $\begin{array}{l}\text { Unión } \\
\text { libre }\end{array}$ & 4 & Prejardín & 3 & $\begin{array}{l}\text { Rodeo } \\
\text { Alto }\end{array}$ & Nuclear \\
\hline 5 & 8 & Finalizada & 23 & $\begin{array}{l}\text { Técnica } \\
\text { en primera } \\
\text { infancia }\end{array}$ & Independiente & $\begin{array}{l}\text { Unión } \\
\text { libre }\end{array}$ & 3 & Prejardín & 2 & $\begin{array}{l}\text { París } \\
\text { Bello }\end{array}$ & Nuclear \\
\hline 6 & 8 & 3 & 24 & $\begin{array}{c}\text { Técnica y } \\
\text { tecnología } \\
\text { en sistemas } \\
\text { de gestión } \\
\text { ambiental }\end{array}$ & Docente & Soltera & 6 & Transición & 2 & Castilla & $\begin{array}{c}\text { Extensa/ } \\
\text { Monoparental }\end{array}$ \\
\hline 7 & 8 & 4 & 24 & $\begin{array}{l}\text { Técnica en } \\
\text { nómina y } \\
\text { prestaciones } \\
\text { sociales }\end{array}$ & Independiente & Soltera & 2 & Párvulos & 3 & $\begin{array}{c}\text { El } \\
\text { Salvador }\end{array}$ & Extensa \\
\hline 8 & 8 & 4 & 35 & $\begin{array}{l}\text { Tecnología } \\
\text { educación } \\
\text { infantil }\end{array}$ & $\begin{array}{l}\text { Docente } \\
\text { preescolar }\end{array}$ & Casada & 4 & Jardín & 2 & $\begin{array}{l}\text { Calatrava } \\
\text { Itagüí }\end{array}$ & Extensa \\
\hline
\end{tabular}

Fuente: elaboración propia

Como técnica de recolección de información se privilegió el uso de la entrevista semiestructurada, pues brinda libertad en la formulación del instrumento, un guion de preguntas abiertas, lo que permite realizar comentarios por fuera de las preguntas planteadas (Sabino, 1992). Esto otorgó mayor fluidez y confianza tanto a las investigadoras como a las participantes. Durante la aplicación de esta técnica, la observación fue un instrumento esencial porque indagó el contexto inmediato de las participantes $y$, de esta forma, captó la información de manera detallada para lograr una mayor comprensión de la situación investigada (Bonilla y Rodríguez, 1997).

Para el análisis de la información se empleó, en primer lugar, la transcripción de datos obtenidos durante la aplicación de las entrevistas y la observación; en segundo lugar, el análisis global, que 
consistió en ordenar los datos obtenidos y codificarlos con base en las categorías de la investigación; y, por último, se realizó un análisis profundo al comparar los resultados con la literatura (Martínez, 2006), lo que llevó finalmente a la discusión y conclusiones de la investigación.

\section{Resultados y discusión}

\section{Ambiente familiar: una mirada desde la cotidianidad del hogar}

El análisis de la información evidencia que si bien cada madre-docente lleva una rutina diferente, todas tienen en común que son las principales encargadas de la planeación, organización y ejecución de cada una de las actividades dispuestas para el día. De acuerdo con los testimonios, en promedio las madres-docentes inician el día a las cinco de la mañana y lo finalizan entre las diez y once de la noche. En el transcurso del día realizan tareas del hogar como la preparación de alimentos y el aseo, además de cumplir con sus obligaciones como estudiantes universitarias y trabajadoras. Así lo expresa una de ellas al referirse al asunto que cree menos agradable del ambiente familiar: "a uno le toca hacer muchas cosas, entonces manejar los tiempos de la universidad, el trabajo, ver con quién dejo a mi hija o qué día puedo hacer esto o lo otro" (entrevistada 1, noviembre 05 de 2019).

Hernández, Cáceres y Linares (2019) demuestran en su estudio que esta situación es común en la población de estudiantes que son madres, "el tiempo se organiza para cumplir con las actividades académicas y de crianza; dos roles que se ven obligados, en el día a día, a asociarse" (p. 46). Además de la falta de tiempo, otros factores que las madres-docentes consideran complicados en el ambiente familiar son la crianza, la relación entre hermanos, el manejo de las pataletas, el estrés y la autoridad en el hogar. 
En este punto toma relevancia el papel que cumple el padre como corresponsable en la crianza. En solo uno de los ocho casos investigados, el padre ejerce plenamente su rol en el ambiente familiar; en los demás casos esta figura está solo en algunos momentos de la jornada como ayudante de la madre, ya sea apoyando en la preparación para el inicio del día, recibiendo ocasionalmente al hijo en su regreso de la escuela, o su presencia definitivamente es nula.

Respecto a esto, una de las participantes expresa: "a veces siento como si no fuera mi esposo o el papá del niño, sino otro hijo" (entrevistada 3, 2 de noviembre de 2019). Bastante semejanza se encuentra con la investigación de Amarís, Camacho y Fernández (2000) acerca del rol del padre en la familia, quienes postulan que:

El padre centra sus actividades de cuidador en aquellas acciones que no le exijan un involucramiento cotidiano y un mayor esfuerzo, es decir, las actividades que realiza dependen, en su mayoría, de circunstancias ocasionales que le permiten proporcionar cuidados a sus hijos: cuidarlos cuando se enferman, llevarlos al médico, etc. Esto nos hace entender que el padre sigue considerándose una persona secundaria en el cuidado de los hijos. (p. 162)

De igual forma, en la mayoría de los casos, los abuelos se presentan como acompañantes ocasionales. Este aspecto es importante, porque si bien está claro que el cuidado de los hijos es responsabilidad de los padres, estos requieren la ayuda de una red de apoyo cercana y permanente. No obstante, en los casos investigados se evidencia que esta responsabilidad recae en mayor medida sobre las madres.

Es comprensible, entonces, que las participantes expresen que disfrutan más del ambiente familiar durante el momento de descanso, el tiempo de conversación y compartir en familia: "el tiempo en que ya se acabaron las actividades y estamos viendo una película, comemos crispetas y ya no tengo que estar en la cocina o 
Ilevándola a algún lado o haciendo algo, sino que es el tiempo para nosotras" (entrevistada 2, 11 de diciembre de 2019).

Ahora bien, las madres-docentes resaltan como factores esenciales del ambiente familiar los valores, las normas y la comunicación. Una de ellas da esta definición:

El ambiente familiar es un espacio en donde se trabajan diferentes normas, también es un espacio que nos permite compartir en familia, donde se escuchan los intereses de cada uno y se potencian las habilidades, se disfruta, se quiere, se está en familia. (Entrevistada 8, 26 de octubre de 2019)

Gallego, Pino, Álvarez, Vargas y Correa (2019) ratifican que las representaciones que forman las familias de sí mismas muestran una relación con las experiencias socioafectivas y las interacciones entre los integrantes del grupo familiar. Por este motivo "la familia es la encargada de pasar de generación en generación la cultura" (p. 141). En efecto, la cultura es otro aspecto que destaca en los testimonios de las madres-docentes, al igual que las prácticas de crianza y las costumbres. Una participante afirma que "en el ambiente familiar de nosotros se ven muchos valores, muchas responsabilidades, todos tienen su rol. El ambiente familiar también tiene unas exigencias, está impregnado de una cultura que viene desde los abuelos" (entrevistada 6, 26 de octubre de 2019).

Dentro de esta definición de ambiente familiar salen a la luz características como el amor, el diálogo, el respeto, la tolerancia y la dedicación a los hijos. De igual forma, las madres-docentes concuerdan en que en el ambiente familiar se realiza un proceso tanto formativo como educativo. Evidencia de ello es el siguiente relato: "yo creo que uno forma como persona, con valores y todo eso, pero yo, que me estoy formando como docente, educo mucho a mi hija en muchas cosas que le sirven para el jardín" (entrevistada 5, 23 de octubre de 2019). 
Las percepciones de las participantes apuntan a que se forma en valores y se educa en conocimientos, lo que indica que el proceso formativo es un componente esencial para el progreso de los hijos. Por tanto, la familia es un apoyo crucial para que ellos y la escuela logren un adecuado desarrollo de las dimensiones educativas y sociales (Rodríguez y Viveros, 2013).

Por otro lado, en los testimonios de las madres-docentes se evidencian sentimientos de culpa y frustración con respecto a sus acciones. Sin embargo, todas consideran que hacen lo posible por desempeñar correctamente su papel como madres:

Yo muchas veces me he sentido frustrada y triste por el acompañamiento, porque no puedo estar en momentos muy importantes para mi hijo por el estudio, entonces es un poco complicado en ese sentido. En el rol de madre me siento excelente, porque uno tiene errores, para mí uno de esos es el acompañamiento, pero en lo demás uno sí desarrolla ese instinto de madre y hace el acompañamiento desde lo que más se pueda. (Entrevistada 7, 24 de octubre de 2019)

En este marco de ideas, el acompañamiento se presenta como una de las condiciones principales que deben garantizar el ambiente familiar y los miembros de este para que los niños se sientan motivados y apoyados. Esta posición es respaldada por Flórez, Villalobos y Londoño (2017), quienes consideran que:

Cuando se describen las acciones educativas hay un proceso dialógico, el cual permite dirigirse a las personas y a los miembros significativos responsables de su proceso de acompañamiento y en su interacción con el cuidado, el apoyo y la orientación que deben recibir los estudiantes para fortalecerles como ciudadanos integrales. (p. 199)

De igual forma, las participantes concuerdan en que es necesario transmitir a sus hijos seguridad y tranquilidad, demostrando con el ejemplo y con hechos la importancia de la educación: 
El acompañamiento es indispensable, el amor que uno le muestre a ellos, porque ellos sienten miedo de que uno los va a abandonar, entonces la seguridad que uno como papá le pueda transmitir al niño, de que no es un abandono, sino que es un proceso. (Entrevistada 5, 23 de octubre de 2019)

\section{La docente y la interacción como protagonistas en el ambiente escolar}

En orden de importancia para la educación y formación de los niños y niñas, el ambiente escolar ocupa el segundo lugar después del ambiente familiar, puesto que "por ser un entorno directo de socialización, permea en todos los aspectos que hacen parte del individuo, llevándolo a relacionarse con sus semejantes y a aceptar las diferencias que cada uno posee" (Jaramillo y Guzmán, 2019, p. 154). Una de las madres-docentes define el ambiente escolar como "un centro, una institución o un espacio donde se educa, se aprende" (entrevistada 1, 5 de noviembre de 2019). Las demás entrevistadas concuerdan con esta concepción, pero agregan en sus testimonios elementos como el aprendizaje de rutinas, el compartir con los compañeros y el cumplimiento de objetivos y logros. De esta manera, una participante afirma:

El ambiente escolar es un acompañamiento, es una interacción con el entorno, donde ellos adquieren aprendizajes no solo de la docente sino de sus compañeros, donde le fundamentan muchas bases que en la casa le dieron, la escucha, la tolerancia, el respeto por sí mismo y por el otro. (Entrevistada 7, 24 de octubre de 2019)

Redondo (2016) complementa esta definición al afirmar que "Ios ambientes escolares son el resultado de la confluencia continua de factores sociales, políticos, económicos y culturales del contexto en el que estos se sitúan, y de las condiciones y características de quienes circulan en ellos" (p. 3). Al hablar de elementos caracterís- 
ticos del ambiente escolar, la docente toma el protagonismo como la figura encargada de enlazar todos sus componentes, entre ellos la socialización, el compañerismo, el aprendizaje y las experiencias.

Dadas estas condiciones, hay un consenso entre las madresdocentes sobre el hecho de que en el ambiente escolar se realiza un proceso formativo y educativo. Una de las participantes lo expone así:

Puede ser educativo y formativo, los dos, porque de alguna manera mi hijo se va a educar en saberes, pero también se va a formar a la hora de compartir, de seguir reglas, de saber que tiene una rutina, de cumplir horarios y otras mil cosas que se le van a presentar. (Entrevistada 8, 26 de octubre de 2019)

En este punto, toma relevancia la interacción de los niños en el ambiente escolar, asunto en el que Olivos (2010) sostiene que:

Desde un punto de vista sociocultural, es posible reconocer en el aula factores sociales destinados a la reproducción de roles y modelos de interacción, derivados de condiciones culturales dominantes que se expresan en la infraestructura escolar y se perpetúan estandarizados por las prácticas educativas. Estas condicionantes de la triada cultura-aprendizaje-ambiente requieren para su análisis integrar la interpretación de las interacciones personales y de las propiedades físicas del ambiente escolar. (p. 206)

La mayoría de las madres-docentes concuerdan en que las interacciones que tienen los niños en cada uno de los ambientes inciden en su funcionamiento familiar y escolar. Una de ellas manifiesta:

Los niños son una esponjita, que van botando de a goteritas todo lo que van haciendo, lo que va pasando y a veces pasan muchas situaciones en el ambiente escolar que se ven reflejadas inmediatamente en el familiar y vi- 
ceversa. Por eso digo yo que todo es un hilo conductor. (Entrevistada 5, 23 de octubre de 2019)

La socialización y la interacción son elementos primordiales en la formación de los niños, por lo que las participantes dan relevancia a que ellos puedan aprender a compartir y fortalecer la resolución de conflictos, lo que evalúan como un factor positivo de este ambiente:

Yo creo que lo mejor de ese ambiente es la manera como socializan entre ellos, puede que la profe no tenga muchas estrategias, pero ellos aprenden del otro, ellos aprenden imitando al otro. Entonces la socialización con el otro para mí es fundamental. (Entrevistada 3, 2 de noviembre de 2019)

Con base en estas apreciaciones, las madres-docentes consideran que el ambiente escolar debe garantizar las condiciones necesarias para que los niños permanezcan motivados en el proceso escolar. En este marco, la docente es la encargada directamente de motivar a partir de la metodología que emplee, de la manera de expresarse y de la forma en que demuestre afecto hacia los niños. No obstante, si bien la docente tiene un papel primordial, también se debe tener una mirada global del ambiente escolar, por tanto:

Es indispensable una sintonía entre los aspectos físicos (el espacio, la limpieza, los materiales, ventilación e iluminación, mobiliario, materiales, orden, entre otros), los socioemocionales (el respeto, la tranquilidad, relaciones interpersonales armoniosas, comunicación, autocontrol, entre otros) y los de aprendizaje (participación, motivación por aprender, metodologías innovadoras y lúdicas, dinamismo, preparación de las docentes, entre otros). (Castro y Morales, 2015, p. 28)

Por otro lado, un aspecto a mejorar es la complicada relación entre los padres de familia y la docente, considerando la influencia 
de los primeros en el ambiente escolar. Al respecto, una madredocente expone:

Se trabaja constantemente para el padre, para mostrar resultados y no para el niño, yo creo que los papás están exigiendo un montón de cosas y no dejan que los niños sean. El ambiente escolar tiene que ser un ambiente muy sano, donde siempre se esté trabajando en pro del niño, no en pro del padre. Mientras se piense en el niño, él siempre va a querer ir. (Entrevistada 2, 11 de diciembre de 2019)

Asimismo, las madres-docentes manifiestan que es importante equilibrar la formación cognitiva y la formación del ser. Además, varias participantes concuerdan en que la preparación de la docente hace la diferencia en este ambiente. Una de ellas afirma que "las maestras muchas veces no son muy preparadas o se preparan, pero no lo aplican y yo creo que eso es lo que hay que mejorar. Ser maestras coherentes" (entrevistada 5, 23 de octubre de 2019). Desde esta perspectiva, se supone que la maestra integre y equilibre su preparación y su aplicación. Por lo tanto, también se espera que:

Posea habilidades de intervención familiar, que le permitan orientar a la familia en estrategias relacionadas con el acompañamiento infantil; debido a que el desarrollo profesional del maestro no se queda única y exclusivamente circunscrito al ámbito escolar; es por ello que las instituciones esperan del personal docente la puesta en marcha de actividades pedagógicas que dinamicen el acompañamiento del niño en su hogar. (Ospina y Gallego, 2014, p. 280)

En este sentido, dentro de los testimonios destaca el siguiente, que describe funciones que la maestra debe cumplir:

El adecuado acompañamiento de cada uno de los niños: a pesar de que son un grupo, yo creo que uno como docente puede reconocer los gustos y cada una de las cosas 
de los niños. Tener acompañamiento con la familia: uno como docente se da cuenta cuando hay un problema familiar, cuando el niño está triste, cuando el niño siente algo por alguien. Hacerle ese acompañamiento, no solamente en tenerle que enseñar, sino también más en la parte emocional del niño. (Entrevistada 4, 22 de octubre de 2019)

\section{Estrategias de acompañamiento: acciones, temores y formación académica}

Las madres-docentes definen las estrategias de acompañamiento a partir de acciones como establecer horarios y normas, explicar, acompañar, organizar, ayudar, aconsejar, supervisar, guiar, asistir a la institución educativa cuando se requiera y tener buena comunicación con los docentes. Una de las participantes define así las estrategias de acompañamiento:

Las actividades que pueda realizar con mi hija estando en la casa para acompañar el proceso en la institución, para que ella se anime a ir a la institución o para que aprenda cosas que tal vez en la institución no se las enseñan. (Entrevistada 4, 22 de octubre de 2019)

Otra participante complementa esta definición: "Io que nosotros como padres, cuidadores o demás, aportamos para que mi hijo tenga un mejor vínculo social, académico, familiar. Es el aporte que nosotros hacemos para que él cumpla sus logros y objetivos a nivel escolar" (entrevistada 3, 2 de noviembre de 2019).

En este orden de ideas, las estrategias de acompañamiento son entendidas como la manera en que los adultos aportan en el proceso social y formativo de los niños, acompañando y apoyando en cada etapa:

Por tanto, los padres, madres o acudientes que acompañan a sus hijos o hijas les trasmiten mayor seguridad 
y confianza a la hora de afrontar retos. Es a partir del constante diálogo entre los miembros de la familia que se crean las estrategias que deben implementar, las pautas por seguir y las formas de hacer frente a los caminos que conducen a alcanzar el logro. (Villalobos, Flórez y Londoño, 2017, p. 64)

Ahora bien, la manera que tiene cada madre-docente de acompañar a los hijos es muy similar; en todos los testimonios resalta el hecho de que son ellas como madres, quienes acompañan en el hogar durante la realización de los compromisos escolares. En algunos casos, los papás tienen un rol secundario o nulo en este aspecto. Se destacan como factores esenciales de acompañamiento: la tranquilidad, el silencio, la seguridad, la independencia, la atención y la compañía que brindan las madres a sus hijos.

Frente al acompañamiento recibido por parte de las instituciones educativas en las que se encuentran los hijos, las madres-docentes señalan que se presenta cuando los niños hacen parte de la institución, hay poco o nulo acompañamiento previo al ingreso. No obstante, las madres-docentes manifiestan que el primer día de clase los niños ingresan tranquilos y no tienen inconvenientes de adaptación, debido a que la familia realiza una preparación, porque las madres-docentes reconocen su importancia.

Sin embargo, llama la atención que las mamás, los papás, y en algunos casos los abuelos, presentan dificultades cuando el niño ingresa al ambiente escolar; incluso algunas participantes manifiestan que los abuelos se deprimen, que la familia extraña al niño en la casa o que quieren ir rápidamente por él a la escuela:

El primer día para mí fue horrible. Yo lloré mucho en la universidad, mucho. Pero yo la llevé y ella estaba supercontenta [...] uno como profesora dice "ay, pero las mamás por qué se ponen a llorar" y uno como mamá dice "no, eso es superdifícil", uno solamente lo entiende cuando es mamá. Es superdura esa entrada, pero a ella le fue 
muy bien en la adaptación, en todo, ella nunca lloró. (Entrevistada 5, 23 de octubre de 2019)

Esto indica que, en efecto, las familias preparan al niño para el ingreso, pero dejan de lado su propia preparación. Abello (2009) lo ratifica así:

El cambio para los padres y madres de familia implica movilización de los roles paterno y materno. Por una parte, supone el gozo de ver crecer a su hijo o hija y verle enfrentar exitosamente nuevas situaciones, pero por otro implica preocupación por la adaptación al cambio. (p. 938)

En cuanto a la integración de la familia en las dinámicas escolares, se evidencia que las madres son quienes en mayor medida asumen la responsabilidad de asistir a la entrega de informes, con algunas excepciones donde también acompañan el padre o los abuelos. En contraste, cuando se presentan actividades o integraciones en la institución, por lo general asiste todo el núcleo familiar.

Con los testimonios brindados por las madres-docentes, se identifican algunas estrategias de acompañamiento puntuales de parte de las instituciones educativas donde asisten sus hijos (tabla 2) y de ellas como madres-docentes (tabla 3 ).

Tabla 2. Estrategias de acompañamiento institucional.

\begin{tabular}{|l|l|}
\hline \multicolumn{1}{|c|}{ Aspecto } & \multicolumn{1}{c|}{ Acciones } \\
\hline Información y comunicación & $\begin{array}{l}\text { • Emplear un comunicador o agenda donde se informan } \\
\text { las actividades del día a día. } \\
\text { •Informar con anticipación las actividades de cada mes. }\end{array}$ \\
\hline Adaptación & $\begin{array}{l}\text { - Organizar una semana de prueba, donde los niños van } \\
\text { acompañados de sus padres o adultos significativos y } \\
\text { se realiza la jornada cotidiana. } \\
\text { - La docente envía a las madres videos y fotos de sus } \\
\text { hijos durante el periodo de adaptación. }\end{array}$ \\
\hline
\end{tabular}

Fuente: elaboración propia 
Tabla 3. Estrategias de acompañamiento de las madres-docentes

\begin{tabular}{|c|c|}
\hline Aspecto & Acciones \\
\hline $\begin{array}{l}\text { Información de la } \\
\text { institución }\end{array}$ & $\begin{array}{l}\text { - Instalar la información en un lugar visible y señalar cada actividad próxima para } \\
\text { tener todo preparado. }\end{array}$ \\
\hline $\begin{array}{l}\text { Participación del } \\
\text { padre }\end{array}$ & - Dividir la asistencia a la institución: en una ocasión va el papá y en otra la mamá. \\
\hline Tiempo & $\begin{array}{l}\text { - El factor común es la anticipación, pensar a futuro, prever horarios y } \\
\text { disponibilidad. } \\
\text { - Matricular al hijo en la institución donde trabaja la madre, con el fin de conseguir } \\
\text { mayor comodidad para todos, sobre horarios y desplazamientos. } \\
\text { - Alargar la jornada diaria hasta altas horas de la noche para cumplir compromisos } \\
\text { de la universidad y del trabajo. } \\
\text { - Disponer los fines de semana para compartir con la familia. } \\
\text { - Intentar que todas las vacaciones sean para pasar tiempo con los hijos. } \\
\text { - Organizar el horario de clases de acuerdo con el horario de estudio de los hijos } \\
\text { y con el horario laboral. }\end{array}$ \\
\hline $\begin{array}{l}\text { Actividades } \\
\text { extracurriculares }\end{array}$ & $\begin{array}{l}\text { - Inscribir a los niños y niñas en actividades fuera del ambiente escolar, como } \\
\text { natación, equitación o futbol. } \\
\text { - Asistir a este tipo de actividades para liberar estrés y enseñar al hijo que cada } \\
\text { uno tiene su espacio. }\end{array}$ \\
\hline $\begin{array}{l}\text { Preparación de } \\
\text { los hijos para } \\
\text { el ingreso al } \\
\text { ambiente escolar }\end{array}$ & $\begin{array}{l}\text { - Involucrar a los hijos en la compra del uniforme y de los útiles escolares. } \\
\text { - Pasar por la institución y recalcar al hijo que esa será su nueva escuela. } \\
\text { - Acompañar el primer día de ingreso. } \\
\text { - Tomar como ejemplo a la madre, para motivar la asistencia al ambiente escolar: } \\
\text { "debes ir a estudiar, como la mamá". } \\
\text { - Mostrar imágenes y videos sobre la escuela. }\end{array}$ \\
\hline Recomendaciones & $\begin{array}{l}\text { - Seguir las recomendaciones de profesionales como psicólogos, nutricionistas } \\
\text { y docentes. }\end{array}$ \\
\hline $\begin{array}{l}\text { Elementos físicos } \\
\text { o externos dentro } \\
\text { del hogar }\end{array}$ & $\begin{array}{l}\text { - Crear una cartelera de estímulo-respuesta, donde cada acción del niño se } \\
\text { aprueba o reprueba con una imagen feliz o triste, y de acuerdo con el número de } \\
\text { imágenes felices se da un premio. } \\
\text { - Aplicar el método Glenn Doman, con el que se busca estimular el aprendizaje } \\
\text { mediante una enseñanza receptiva, con palabras e imágenes usadas en la } \\
\text { cotidianidad (Querevalú, 2019). } \\
\text { - Contar con una docente externa para el acompañamiento educativo del hijo y, } \\
\text { de esta manera, separar su rol de madre con el de docente. }\end{array}$ \\
\hline $\begin{array}{l}\text { En el aula como } \\
\text { docentes }\end{array}$ & $\begin{array}{l}\text { - Acompañar de manera grupal e individual. } \\
\text { - Manejar la autoridad. } \\
\text { - Permitir la exploración. } \\
\text { - Brindar amor y cariño. } \\
\text { - Motivar. }\end{array}$ \\
\hline
\end{tabular}


Un elemento importante dentro de las narraciones de las participantes es la formación académica que han recibido. Ellas indican que tiene gran incidencia en su rol como madres en aspectos como la crianza, la manera de educar y acompañar en el hogar, en conocimientos sobre las exigencias que se pueden hacer a las instituciones educativas donde están sus hijos y para hacer evaluaciones sobre aprendizajes teóricos y prácticos de los docentes que acompañan a los niños. También se destaca la posibilidad que tienen de seguirse preparando y adquiriendo más herramientas que les ayuden en su labor como madres y docentes. En este propósito, se puede afirmar que las madres-docentes viven la maternidad de una manera "mujer-madre", la cual "implica una equivalencia entre las aspiraciones individuales y la maternidad y envuelve una idea de equilibrio. Por combinar el desarrollo profesional y la realización familiar" (Arias, 2018, p. 165).

Por otro lado, es relevante el papel de la docente en la universidad. Es decir, más que en los cursos, el currículo o el plan de estudios de la universidad, las participantes hacen énfasis en la docente que dicta dichos cursos y en su influencia para motivarlas a continuar en su formación como profesionales de la educación.

En los testimonios se identifica que las madres-docentes tienen claro qué se debe hacer en el aula y qué se puede aplicar de acuerdo con sus conocimientos teóricos y prácticos, pero manifiestan que es difícil encontrar la manera de aplicarlo en su hogar. En esta situación emerge una separación de roles de docente y madre; en palabras de una de las participantes: "no puedo decir que soy una maestra en la casa, porque en la casa soy una mamá" (entrevistada 2, 11 de diciembre de 2019). Esto quiere decir que, si bien las participantes son madres y docentes, en cada uno de los ambientes en los que interactúan separan sus roles. Frente a esto, otra de las participantes manifiesta que "es complicado llevarlo, porque como se dice 'en casa de herrero azadón de palo', uno puede darle un consejo a un papá como profe, pero uno como papá a veces es más ofuscado, entonces es un poquito difícil" (entrevistada 8, 26 de octubre de 2019). 
Por último, cabe resaltar que las madres-docentes reconocen que es necesario ser parte de ambos ambientes para comprenderlos y ser conscientes de las responsabilidades que deben cumplirse en cada uno, al igual que los roles que los miembros que los conforman deben asumir. De esta manera, coinciden con el argumento de que, sin ser madre es difícil comprender este rol y sin ser docente es complicado ponerse en su lugar.

\section{Conclusiones}

Los resultados obtenidos permitieron analizar de manera global y profunda las estrategias de acompañamiento que emplean las madres-docentes durante el paso de sus hijos del ambiente familiar al escolar.

Para llegar a este análisis, fue necesario describir el ambiente familiar a partir de la experiencia de las madres-docentes $y$, con base en la definición y caracterización que ellas brindaron, se logra entender el ambiente familiar como un espacio donde priman las normas y los valores, como bases construidas sobre el respeto, el amor, la tolerancia, la comunicación y el acompañamiento, siendo este último una condición principal que debe garantizar dicho ambiente.

El ambiente familiar gira en torno a una rutina que se crea en la cotidianidad de la familia, de acuerdo con las obligaciones y roles de los miembros que la componen, por lo cual son fundamentales el papel del padre y el de los abuelos para la construcción de una red de apoyo que acompañe a la madre en la crianza de los hijos.

Por otro lado, el ambiente escolar se caracteriza desde la perspectiva de las madres-docentes, mediante las definiciones y descripciones dadas por ellas. De esta forma, se concluye que el ambiente escolar es un espacio de aprendizaje, socialización, interacción y compañerismo, donde la docente cumple un rol principal al ser la figura de enlace entre estos aspectos. 
La docente debe propiciar entornos experienciales y significativos mediante la forma de expresarse y la demostración de afecto hacia sus estudiantes. Por esto, se espera que cumpla con numerosos componentes relacionados con su preparación y aplicación de metodologías en el aula que mantengan la motivación en los estudiantes. Entre estos componentes se encuentra la relación con los padres de familia, lo que según las participantes es un aspecto que debe mejorar, puesto que en ocasiones se dificulta tener una buena comunicación entre ambas partes.

Un factor común dentro de los resultados es que las madresdocentes relacionan la formación con los valores y la educación con el conocimiento. Las percepciones apuntan a que en el ambiente familiar y el escolar se lleva un proceso tanto educativo como formativo, lo que indica la importancia de establecer una comunicación asertiva entre ambas partes, pues son los dos ambientes principales en el desarrollo integral de los niños y niñas.

Todo lo anterior permite identificar las estrategias de acompañamiento que emplean las madres-docentes, de los cuales se destacan cinco elementos:

1. Con base en las características que proponen las participantes, las estrategias de acompañamiento pueden definirse como la manera en que los adultos - ya sean los padres, los abuelos o la docente- aportan en el proceso educativo y formativo de los niños, propiciando el alcance de logros y objetivos en los aspectos personal, social y académico.

2. La preparación para el ingreso de los niños al ambiente escolar es realizada únicamente por la familia, mientras las instituciones educativas ofrecen poco o nulo acompañamiento. Esto es relevante porque demuestra la importancia que la familia da a la preparación para el ingreso de los niños y porque invita a las instituciones a revisar sus acciones en el periodo de adaptación de los niños al ambiente escolar. 
3. La adaptación al ambiente escolar es un asunto complicado para los niños y sus familias. En efecto, las familias acompañan y preparan a los hijos, pero no encuentran la manera de prepararse y adaptarse a la nueva experiencia que supone que los hijos ingresen al ambiente escolar. El ingreso al ambiente escolar del niño requiere de una adaptación de la familia, aspecto que las instituciones deben tener en cuenta, ya que no se trata solo de aplicar un periodo de adaptación para que los niños se motiven a estar en el nuevo ambiente, también se debe pensar en el acompañamiento que se brinda a las familias para que adapten su rutina a las nuevas condiciones.

4. La formación académica de las madres-docentes es un factor de gran incidencia en su rol como madres en aspectos como la crianza y la manera de acompañar en el hogar. Además, la adquisición de conocimientos es importante para exigir una atención y acompañamiento de calidad en las instituciones educativas donde están sus hijos y para evaluar los comportamientos y acciones de las docentes que los acompañan.

5. El compromiso de las madres-docentes con el acompañamiento de los hijos es fundamental, pues ellas son quienes apoyan más la realización de compromisos escolares y quienes asisten a las entregas de informes escolares. Sin embargo, es evidente la tensión de la separación de roles en los ambientes en que interactúan, pues para ellas es necesario ser mamá en la casa y docente en la escuela, pero no pueden cumplir ambos roles en cada ambiente.

Este análisis permitió obtener una visión bidireccional de las estrategias de acompañamiento que emplean las madres-docentes, tanto en el ambiente familiar como en el escolar. Con esto se espera reducir un poco la brecha en la perspectiva que se tiene de cada uno de los ambientes y de las responsabilidades de los miembros que los conforman. 


\section{Referencias bibliográficas}

Abello, R. (2009). Construyendo sentido sobre las transiciones al inicio de la escolaridad. Revista Latinoamericana de Ciencias Sociales, Niñez y Juventud, 7(2), 929-947. Recuperado de http://biblioteca.clacso.edu.ar/ Colombia/alianza-cinde-umz/20130712044726/ArtRocioAbelloCorrea. pdf

Amarís, M., Camacho, R. y Fernández, I. (2000). El rol del padre en las familias con madres que trabajan fuera del hogar. Psicología desde el Caribe, 5, 157-175. Recuperado de https://www.redalyc.org/articulo. oa? id=21300507

Arias, M. (2018). Análisis interseccional de la construcción social de la maternidad: historias de vida de mujeres cuencanas. Revista Latinoamericana de Estudios de Familia, 10(2), 148-168. Recuperado de https://doi: 10.17151/rlef.2018.10.2.9

Bonilla, E. y Rodríguez, P. (1997). Más allá del dilema de los métodos: la investigación en ciencias sociales. Bogotá: Ediciones Uniandes; Grupo Editorial Norma.

Castro, A. y García, R. (2016). Vínculos entre familia y escuela: visión de los maestros en formación. Magis. Revista Internacional de Investigación en Educación, 9 (18), 193-208. Recuperado de https://doi.org/10.11144/ Javeriana.m9-18.vfev

Castro, M. y Morales, M. (2015). Los ambientes de aula que promueven el aprendizaje, desde la perspectiva de los niños y niñas escolares. Revista Electrónica Educare, 19(3), 1-32. Recuperado de http://dx.doi. org/10.15359/ree.19-3.11

Congreso de Colombia. (8 de febrero de 1994). Ley 115, Por la cual se expide la ley general de educación. Diario Oficial $n .^{\circ} 41214$. Recuperado de http://www.secretariasenado.gov.co/senado/basedoc/ ley_0115_1994.html 
Doman, G. (2000). Cómo enseñar a leer a su bebe. EDF. Espitia, R. y Montes, M. (2009). Influencia de la familia en el proceso educativo de los menores del barrio Costa Azul de Sincelejo (Colombia). Investigación y Desarrollo, 17(1), 84-105. Recuperado de http://www.scielo.org.co/ pdf/indes/v17n1/v17n1a04.pdf?

Flórez, G., Villalobos, J. y Londoño, D. (2017). El acompañamiento familiar en el proceso de formación escolar para la realidad colombiana: de la responsabilidad a la necesidad. Revista Psicoespacios, 11(18), 1-25. Recuperado de https://doi.org/10.25057/21452776.888

Gadamer, H. (1993). Verdad y método. Salamanca: Sígueme.

Galeano, M. (2004). Diseño de proyectos en la investigación cualitativa. Medellín: EAFIT.

Gallego, A. M., Pino, J. W., Álvarez, M. M., Vargas, E. D, y Correa, L. V. (2019). La dinámica familiar y estilos de crianza: pilares fundamentales en la dimensión socioafectiva. Hallazgos, 16(32), 131-150. Recuperado de https://doi.org/10.15332/2422409X.5093

Garaigordobil, M. (2014). Conducta prosocial: el papel de la cultura, la familia, la escuela y la personalidad. Revista Mexicana de Investigación en Psicología, 6(2), 146-157. Recuperado de https://www. revistamexicanadeinvestigacionenpsicologia.com/index.php/RMIP/ article/view/191

Hernández, A., Cáceres, F. y Linares, J. (2019). Maternidad en la universidad: postergación del desarrollo personal a la crianza. Revista Virtual Universidad Católica del Norte, 58, 41-57. Recuperado de https:// doi.org/10.35575/rvucn.n58a2

Jaramillo, B. y Guzmán, N. (2019). Las habilidades sociales en los ambientes escolares. Revista Universidad Católica Luis Amigó, 3, 151162. Recuperado de https://doi.org/10.21501/25907565.3263

Martínez, P. (2006). El método de estudio de caso: estrategia metodológica de la investigación científica. Pensamiento \& Gestión, 20, 
165-193. Recuperado de http://rcientificas.uninorte.edu.co/index.php/ pensamiento/article/viewFile/3576/2301

Olivos, P. (2010). Ambientes escolares. En J. Aragonés y M. Amérigo (Eds.), Psicología ambiental (pp. 201-220). Madrid: Pirámide.

Ospina, S. A. y Gallego, A. M. (2014). Desarrollo profesional de los educadores iniciales: una mirada hacia la articulación de su saber y hacer. Revista Colombiana de Ciencias Sociales, 5(2), 276-285. Recuperado de https://www.funlam.edu.co/revistas/index.php/RCCS/ article/view/1394/1288

Querevalú, E. (2019). Desarrollo del proceso de enseñanza aprendizaje en el hogar con el uso del método Glenn Doman [Tesis de especialidad profesional]. Universidad Nacional de Tumbes, Tumbes, Perú. Recuperado de http://repositorio.untumbes.edu.pe/bitstream/ handle/UNITUMBES/1011/QUEREVALU\%20NU\%c3\%91EZ\%20DE\%20 CANALES\%20ELENA\%20AMELIA.pdf?sequence=1\&isAllowed=y

Redondo, M. B. (2016). Formas de interacción social escolar en el nivel preescolar en la Institución Educativa Distrital Nuevo Horizonte [Tesis de maestría]. Universidad de La Salle, Bogotá, Colombia. Recuperado de https://ciencia.lasalle.edu.co/maest_docencia/511/

Rodríguez, A. y Viveros, E. (2013). Sobre la intervención familiar en escenarios educativos: aproximación a una revisión documental. Katharsis, 15, 113-132. Recuperado de https://doi.org/10.25057/25005731.241

Sabino, C. (1992). El proceso de investigación. Caracas: Panapo.

Sánchez, S. (2012). El papel de la familia en la educación [tesis de maestría]. Universidad Internacional de La Rioja, España. Recuperado de https://reunir.unir.net/bitstream/handle/123456789/656/Sanchez\%20 Marta.pdf?sequence $=1$

Sandoval, C. (2002). Investigación cualitativa. Bogotá: Instituto Colombiano para el Fomento de la Educación Superior. 
Secretaría de Educación de Medellín. (2020). Análisis del Sector Educativo. Ambiente escolar. Consultado el 10 de marzo de 2020. Recuperado de https://medellin.edu.co/analisis-del-sector-educativo/ ambiente-escolar

Villalobos, J. L., Flórez, G. A. y Londoño, D. A. (2017). La escuela y la familia en relación con el alcance del logro académico. La experiencia de la Institución Educativa Antonio José de Sucre de Itagüí (Antioquia) 2015. Revista Aletheia, 9(1), 58-75. Recuperado de http://dx.doi.org/10 $.11600 / 21450366.9 .1$ aletheia.58.75

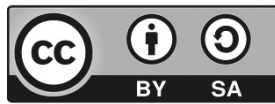

